\title{
Impact of Chronic Emotional Stress on Myocardial Function in Postmenopausal Women and Its Relationship with Endothelial Dysfunction
}

\author{
Hyun Soo Kim, MD and Kyoung Im Cho, MD \\ Division of Cardiology, Department of Internal Medicine, Kosin University School of Medicine, Busan, Korea
}

Background and Objectives: An association between chronic stress and cardiovascular diseases has been described, but the underlying mechanisms have not been fully elucidated. We investigate the impact of perceived stress on the left ventricular (LV) and endothelial functions in postmenopausal women.

Subjects and Methods: We investigated 64 consecutive postmenopausal women (mean age $56.7 \pm 9.7$ years) with atypical chest pain and chronic stress. Patients with coronary heart disease were excluded. Global and segmental longitudinal deformation parameters of LV were used as parameters to assess myocardial function and brachial flow-mediated dilatation (FMD) was used to assess the endothelial function, and patients were analyzed by the Symptom Checklist 90 Revised (SCL-90-R) to determine emotional stress. The study participants were divided into two groups, based on global severity index (GSI): $\geq 50$ (group $A, n=27$ ) or $<50$ (group $B, n=37$ ).

Results: Although there were no significant differences in LV geometry or myocardial performance indices between the groups, global LV strain was significantly reduced in group A compared to group B (-16.6 $2.7 \%$ vs. $-19.1 \pm 1.9 \%, p=0.001)$. There were also significant differences in the value of reactive FMD (6.6 $\pm 2.2 \%$ vs. $9.5 \pm 2.9 \%, p<0.001)$, and same result was observed for nitroglycerine-induced dilatation $(14.6 \pm 4.7 \%$ vs. $18.0 \pm 5.8 \%, p=0.016)$. Multivariate linear regression analysis showed that GSI was the only significant attributor to global LV strain ( $\beta=0.149, p=0.008)$ and reactive FMD ( $\beta=-0.200, p=0.041)$.

Conclusion: Chronic emotional stress may exert negative effects on the LV and endothelial functions, which may be associated with the severity of stress. This study provides a possible mechanism by which stress is associated with an increased risk of cardiovascular dysfunction. (Korean Circ J 2013;43:295-302)

KEY WORDS: Emotional stress; Echocardiography; Endothelium.

\section{Introduction}

Stress is a physical and psychological response to the perceived demands and pressures. ${ }^{1)}$ Converging evidence from experimental

Received: February 6, 2013

Revision Received: March 19, 2013

Accepted: March 29, 2013

Correspondence: Kyoung Im Cho, MD, Division of Cardiology, Department of Internal Medicine, Kosin University School of Medicine, 34 Amnam-dong, Seo-gu, Busan 602-702, Korea

Tel: 82-51-990-6105, Fax: 82-51-990-3005

E-mail:kyoungim74@gmail.com

- The authors have no financial conflicts of interest.

This is an Open Access article distributed under the terms of the Creative Commons Attribution Non-Commercial License (http://creativecommons. org/licenses/by-nc/3.0) which permits unrestricted non-commercial use, distribution, and reproduction in any medium, provided the original work is properly cited. and epidemiological studies indicates that there is an association between chronic psychological distress and cardiovascular disease. ${ }^{2)}$ Psychological stress can cause endothelial distress and dysfunction in humans ${ }^{3 / 4)}$ and animals. ${ }^{566}$ Enhanced sympathetic nerve activity (SNA) plays a major role in the development of atherosclerosis and endothelial dysfunction. Chronic physical pain and mental stress may enhance SNA, and alter the function of the sympathetic nervous system (SNS). Disequilibrium of the autonomic nervous system increases SNS activity at rest, along with a deficiency of SNSmediated responses to certain stimuli, such as postural change or exercise.") The link between psychosocial factors, such as stress and coronary artery disease, has drawn significant attention. Chronic stressful stimuli (such as work stress, marital stress, caregiver strain, low social support, and low socioeconomic status) have been linked to an increased risk of coronary artery disease and other adverse cardiac events. ${ }^{8)}$ There is also evidence that emotional stressors can act 
as triggers for acute cardiovascular events. ${ }^{9)}$ Moreover, the cultural construction of Hwabyung, a Korean culture-bound syndrome, is the occurrence of bodily symptoms in response to distressed emotions associated with the Korean way of perceiving and to intolerable and tragic life situations. Hwabyung usually occurs in middleaged or older women and provides a way of conceptualizing and resolving emotional distress through somatic symptoms, such as chest tightness and palpitation among Korean elderly women. ${ }^{10) 11}$

Therefore, the present study tested the hypothesis that chronic emotional stress may exert negative effects on the myocardial function by measurement of the left ventricular (LV) strain and endothelial functions by measurement of flow-mediated dilatation (FMD) of the brachial artery. ${ }^{12)}$

\section{Subjects and Methods}

\section{Study design and subjects}

Consecutive postmenopausal female subjects with atypical chest pain, who complained of self-labeled chronic stress from December 2011 to July 2012, were enrolled in this study. Chronic stress was defined as suffering from stress for long periods, causing a person to be unable to relax. ${ }^{13)}$ Participants were asked to complete the Symptom Checklist 90 Revised (SCL-90-R) survey, a cardiac echocardiogram, and an exercise stress test. Subjects with ischemic heart disease confirmed by coronary angiography and clinically significant arrhythmia were excluded. Patients with acute stress disorder defined as an anxiety disorder, characterized by a cluster of dissociative and anxiety symptoms occurring within one month of a traumatic event were also excluded. Other exclusion criteria were positive exercise stress tests, congestive heart failure, and significant valvular heart disease. The institutional review board approved this study, and all patients provided written informed consent before participation.

\section{Echocardiographic evaluation}

Standard 2D and strain echocardiographic examinations were performed on all subjects using a 3.5-MHz transducer on the Vivid 7 Dimension ultrasound equipment as they lay in the left lateral decubitus position (General Electric, Horten, Norway). Two-dimensional grayscale imaging (frame rate $\geq 70$ seconds) and color Doppler tissue imaging (frame rate $\geq 115$ seconds) were performed in the apical 2-chamber, 3-chamber and 4-chamber views, using a narrow sector angle. Images from the apical chamber views of the LV were obtained at the end-expiratory apnea and were stored in cineloop format for subsequent offline analysis. Three heartbeats were collected from each view, and a single selected cycle was analyzed off-line using an EchoPAC Dimension system (General Electric, Horten, Nor- way). Peak systolic strains were measured and averaged in order to assess the global longitudinal myocardial regional function (GLS). The endocardial borders were traced at the end-systolic frame, and an automated tracking algorithm outlined the myocardium in successive frames throughout the cardiac cycle. The tracking quality of each segment was verified (with subsequent manual adjustment of the region of interest if necessary), and myocardial motion was analyzed by speckle tracking within the region of interest bound by endocardial and epicardial borders. Inadequate tracked segments were automatically excluded from analysis. In this situation, local strain was calculated in each segment. GLS was obtained by averaging all segment strain values from the apical 4-chamber, 2-chamber, and long axis views.

\section{Brachial artery measurements}

Flow-mediated dilatation was performed using two-dimensional ultrasonography (Vivid 7, General Electronics Corp., Horten, Norway), using a modification of the method of Corretti et al. ${ }^{14)}$ Measurements were performed on the subject's left arm after 10 to 20 minutes of rest in the supine position. The brachial artery was scanned longitudinally just above the antecubital crease using a 10-MHz probe. The diameter of the brachial artery was measured at the $R$ wave of the surface electrocardiogram and at the interface between the tunica media and tunica adventitia of the anterior and posterior wall. Hyperemia was induced by inflation of a pneumatic cuff to 180 to $200 \mathrm{~mm} \mathrm{Hg}$ (50 mm Hg higher than systolic blood pressure) for four minutes, on the most proximal part of the upper arm. The maximal diameter of the brachial artery was measured 45-60 seconds after the sudden deflation of the cuff. The percent brachial artery FMD induced by reactive hyperemia was expressed as the relative change from the baseline [percent FMD $=100 \times\{$ (diameter after hyperemia-baseline diameter)/baseline diameter $\}$ ]. After 15 minutes, a third brachial artery scan was recorded at tre resting state, and the subject was administered a sublingual nitroglycerin $0.4 \mathrm{mg}$ tablet if systolic blood pressure was $\geq 110 \mathrm{~mm} \mathrm{Hg}$. Relative changes in the brachial artery diameter from the baseline to the third examination were expressed as endothelium-independent vasodilatation with or without nitroglycerin. We measured each diameter three times during two heartbeats, and the mean values were used for the final analysis. An independent examiner, who remained blinded to the study, performed the measurements.

\section{Stress assessment by questionnaires}

The SCL-90- $R$ is currently the most reliable and wide-ranging test for screening global psychological distress. ${ }^{15)}$ The SCL-90-R is a validated 90-item multidimensional self-rating questionnaire originally developed to assess the psychopathology of psychiatric and medical 
outpatients. It has been extended to measure psychological distress in a wide range of populations. ${ }^{1516)}$ It assesses a broad range of physical and psychological symptoms that a subject might have experienced in the past seven days. Each of the 90 items is rated on a 5-point scale (ranging from 0 to 4), with higher values indicating greater impairment. The items build nine sub-scales: somatization, compulsivity, interpersonal sensitivity, depression, anxiety, hostility, phobic anxiety, paranoid ideation, and psychoticism. The global severity index (GSI) is derived from all the items, and indicates the degree of overall psychological distress/impairment. Raw scores for the sub-scales and the GSI are between 0-4 ( $0=$ no distress to $4=$ maximal distress). These can be transformed into age and gender-specific normative values (T-value, normal range 50 10 , higher values indicating greater psychological distress) by using a standardization reference table, and a total GSI T-score $\geq 50$ is recommended as optimal for identifying patients with significant psychological distress. ${ }^{1516)}$

Several recent studies have used the SCL-90-R as a measure of mental status and mental health issues in a non-psychiatric setting. ${ }^{17-19)}$ The sub-scales show satisfactory reliability in patients with chronic pain. Cronbach's alpha ranges from $\alpha=0.71$ to $\alpha=0.89$, and the GSI is very consistent, with a Cronbach's alpha of $\alpha=0.97{ }^{20)}$ The study participants were divided into two groups, based on whether their GSI was $\geq 50$ (group A) or $<50$ (group B).

\section{Statistical analysis}

All data are expressed as the mean \pm standard deviation. Data were analyzed using standard statistical software (Statistical Package for the Social Sciences package version 11.0, Chicago, IL, USA), and comparisons of all measurements were made using the independent ttest for continuous variables of two groups and the Pearson correlation test for correlation. To evaluate if the myocardial longitudinal deformation is affected by chronic emotional stress, multivariate linear regression analysis was performed with adjustment of traditional cardiovascular risk factors. A $p<0.05$ was considered statistically significant.

\section{Results}

\section{General characteristics of patients}

There were no significant differences between the high stress group (group A, GSI $\geq 50$ ) and the low stress group (group B, GSI $<50$ ) in clinical, demographic, or laboratory variables (Table 1). The values of somatization, compulsivity, interpersonal sensitivity, depression, anxiety, hostility, phobic anxiety, paranoid ideation, and psychoticism were significantly higher for group A (Table 1).
Table 1. Differences in clinical variables of group $A(G S I \geq 50)$ and $B(G S I<50)$

\begin{tabular}{|c|c|c|c|}
\hline & $\begin{array}{c}\text { Group A } \\
(n=27)\end{array}$ & $\begin{array}{c}\text { Group B } \\
(n=37)\end{array}$ & p \\
\hline Age (years) & $54.0 \pm 8.8$ & $58.3 \pm 10.2$ & 0.075 \\
\hline BMI $\left(\mathrm{kg} / \mathrm{m}^{2}\right)$ & $23.8 \pm 3.4$ & $23.2 \pm 3.4$ & 0.587 \\
\hline Systolic BP (mm Hg) & $130.6 \pm 14.5$ & $126.3 \pm 18.3$ & 0.399 \\
\hline Diastolic BP (mm Hg) & $84.4 \pm 12.5$ & $80.0 \pm 12.8$ & 0.256 \\
\hline Heart rate (/min) & $76.3 \pm 8.4$ & $71.6 \pm 7.9$ & 0.173 \\
\hline Fasting glucose (g/dL) & $104.5 \pm 21.6$ & $97.7 \pm 17.1$ & 0.312 \\
\hline Hemoglobin A1C & $5.9 \pm 0.63$ & $5.7 \pm 0.39$ & 0.272 \\
\hline Serum creatinine (mg/dL) & $0.8 \pm 0.15$ & $0.9 \pm 0.18$ & 0.638 \\
\hline Total cholesterol (mg/dL) & $173.6 \pm 34.2$ & $183.7 \pm 26.9$ & 0.308 \\
\hline LDL-C (mg/dL) & $105.4 \pm 31.2$ & $98.0 \pm 27.1$ & 0.453 \\
\hline TG (mg/dL) & $140.2 \pm 54.9$ & $162.3 \pm 52.1$ & 0.407 \\
\hline $\mathrm{HDL}-\mathrm{C}(\mathrm{mg} / \mathrm{dL})$ & $59.3 \pm 18.9$ & $53.2 \pm 12.5$ & 0.289 \\
\hline hs-CRP (mmol/L) & $2.58 \pm 4.76$ & $0.58 \pm 0.75$ & 0.198 \\
\hline TSH (mIU/L) & $1.16 \pm 0.20$ & $1.18 \pm 0.17$ & 0.348 \\
\hline Free T4 (pmol/L) & $4.06 \pm 8.14$ & $1.92 \pm 1.37$ & 0.729 \\
\hline History of HRT, n (\%) & $3 / 27(11)$ & 9/37 (8) & 0.316 \\
\hline Duration of menopause (years) & $2.01 \pm 1.78$ & $2.33 \pm 1.94$ & 0.374 \\
\hline Somatization & $57.1 \pm 11.4$ & $49.6 \pm 7.4$ & $<0.001$ \\
\hline Compulsivity & $54.9 \pm 8.7$ & $41.2 \pm 5.7$ & $<0.001$ \\
\hline Interpersonal sensitivity & $51.6 \pm 9.3$ & $41.3 \pm 6.8$ & $<0.001$ \\
\hline Depression & $57.3 \pm 10.2$ & $44.3 \pm 7.1$ & $<0.001$ \\
\hline Anxiety & $56.5 \pm 7.8$ & $45.6 \pm 4.6$ & $<0.001$ \\
\hline Hostility & $54.8 \pm 9.3$ & $46.6 \pm 7.2$ & $<0.001$ \\
\hline Phobic anxiety & $58.3 \pm 13.4$ & $45.3 \pm 4.7$ & $<0.001$ \\
\hline Paranoid ideation & $53.7 \pm 9.5$ & $42.3 \pm 4.0$ & $<0.001$ \\
\hline Psychoticism & $53.3 \pm 9.2$ & $42.9 \pm 3.9$ & $<0.001$ \\
\hline Post stress disorder index & $58.7 \pm 8.3$ & $46.3 \pm 7.7$ & $<0.001$ \\
\hline
\end{tabular}

All values are means \pm SD. GSI: global severity index, BMI: body mass index, BP: blood pressure, LDL-C: low density lipoprotein-cholesterol, TG: triglyceride, HDL-C: high density lipoprotein-cholesterol, hs-CRP: high-sensitivity C-reactive protein, TSH: thyroid stimulating hormone, T4: levothyroxin, HRT: hormone replacement therapy

\section{Strain echocardiographic findings}

Global LV systolic function, LV chamber dimension, and LV mass index were normal in all patients with stress. There were no significant differences in the mitral inflow parameters or diastolic function between groups A and B. However, the values of the peak systolic LV strains of group A were significantly lower in three apical views, including the apical long axis view, the apical 4-chamber view, and the apical 2-chamber view, compared to group B (Fig. 1, Table 2). The GLS of group $A$ was also significantly different compared with that of group B (-16.6 $\pm 2.7 \%$ vs. $-19.1 \pm 1.9 \%, p<0.001)$. Inter-observer and intra-observer variability was corrected for by independent analysis by two independent observers (C.K.I and H.S.K.) and by re- 

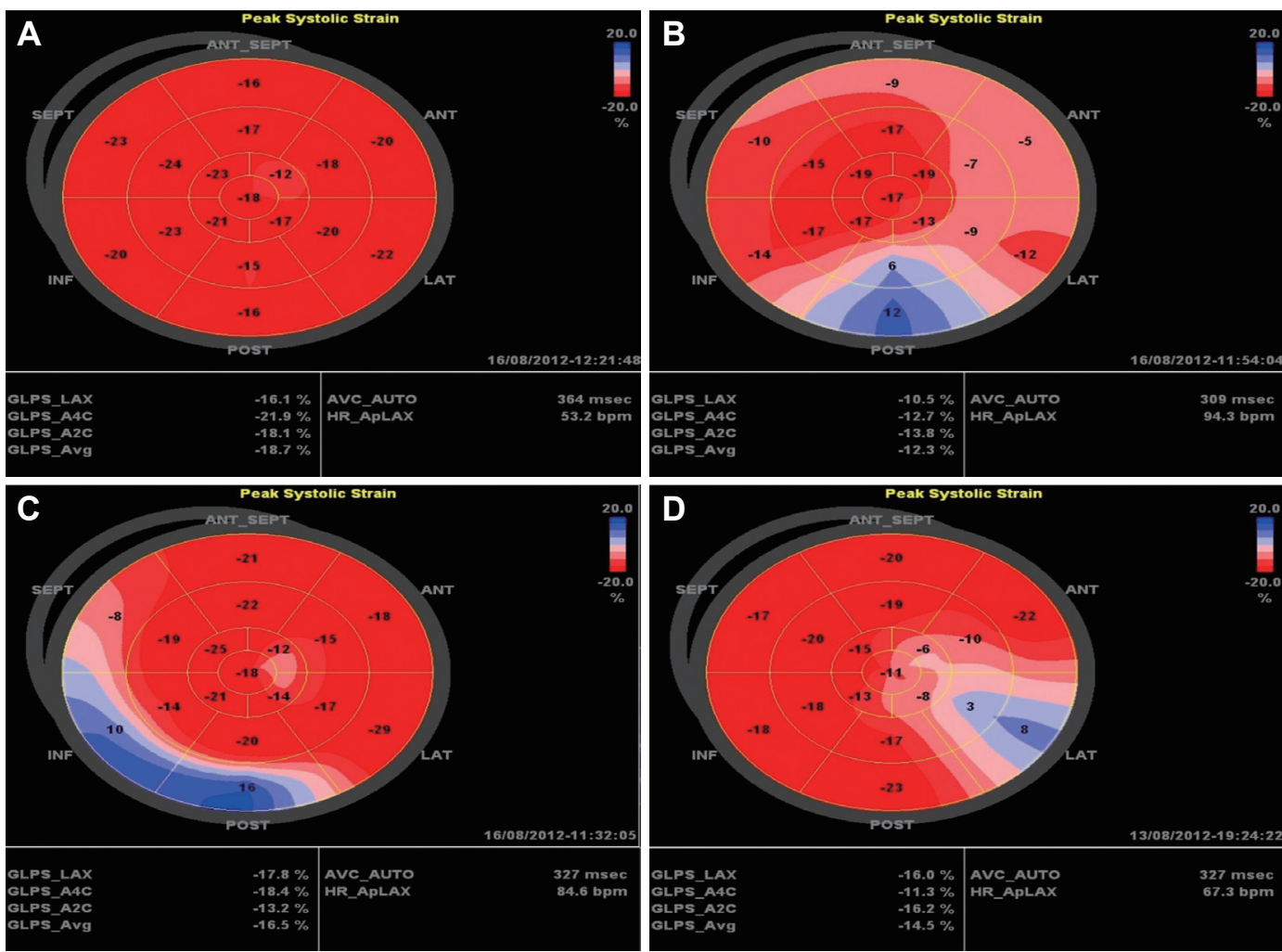

Fig. 1. Bull's eye pattern analyses in patients with stress using two-dimensional speckle tracking strain analysis. A: a subject without stress, showed normal segmental and global left ventricular strain. However, subjects with high stress, such as B (global severity index, GSI=74) and C (GSI=68), D (GSI=72), showed abnormal segmental and global left ventricular strain. GSI: global severity index.

Table 2. Parameters of two-dimensional echocardiography between group $A$ $(G S I \geq 50)$ and $B(G S I<50)$

\begin{tabular}{lccr}
\hline & $\begin{array}{c}\text { Group A } \\
(\mathbf{n}=\mathbf{2 7})\end{array}$ & $\begin{array}{c}\text { Group B } \\
(\mathbf{n}=\mathbf{3 7})\end{array}$ & p \\
\hline LVEDd $(\mathrm{mm})$ & $46.6 \pm 3.3$ & $45.7 \pm 2.5$ & 0.396 \\
EF $(\%)$ & $65.2 \pm 2.1$ & $65.3 \pm 2.3$ & 0.823 \\
LVMI $\left(\mathrm{g} / \mathrm{m}^{2}\right)$ & $99.9 \pm 18.6$ & $99.2 \pm 26.1$ & 0.914 \\
LAD (mm) & $38.2 \pm 3.0$ & $38.4 \pm 2.3$ & 0.838 \\
E velocity (cm/sec) & $72.8 \pm 13.6$ & $74.2 \pm 11.8$ & 0.354 \\
A velocity (cm/sec) & $68.9 \pm 8.9$ & $67.5 \pm 9.1$ & 0.437 \\
Ea velocity (cm/sec) & $8.7 \pm 2.3$ & $7.7 \pm 2.4$ & 0.121 \\
E/Ea & $9.5 \pm 3.3$ & $9.7 \pm 2.3$ & 0.888 \\
Peak systolic strain (\%) LAX & $-16.6 \pm 4.2$ & $-18.8 \pm 2.6$ & 0.024 \\
Peak systolic strain (\%) A4C & $-15.5 \pm 6.9$ & $-19.0 \pm 2.1$ & 0.017 \\
Peak systolic strain (\%) A2C & $-13.5 \pm 10.5$ & $-19.4 \pm 2.1$ & 0.007 \\
Global LV strain (\%) & $-16.6 \pm 2.7$ & $-19.1 \pm 1.9$ & $<0.001$ \\
Reactive FMD (\%) & $6.6 \pm 2.2$ & $9.5 \pm 2.9$ & $<0.001$ \\
NTG dilatation (\%) & $14.6 \pm 4.7$ & $18.0 \pm 5.8$ & 0.013 \\
\hline
\end{tabular}

All values are means \pm SD. GSI: global severity index, LVEDd: left ventricular end diastolic dimension, EF: ejection fraction, LVMI: left ventricular mass index, LAD: left atrial dimension, E: peak early diastolic mitral flow velocity, A: peak late diastolic mitral flow velocity, Ea: peak early diastolic annular velocity, LAX: apical long axis view, A4C: apical 4-chamber view, A2C: apical 2-chamber view, FMD: flow-mediated dilatation, NTG: nitroglycerine, LV: left ventricular peated measurement of these segments on another occasion by the same observer. The intra-observer regression coefficient was 0.92 and the inter-observer regression coefficient was 0.88 . The main cause of inter-observer variability was the different locations of the sample volume. Once the sample volume was placed at a mutually agreed-upon location within the myocardium, measurements became virtually identical.

\section{Brachial artery flow-mediated dilatation}

The parameters of the endothelial function of patients are shown in Table 3. There were significant differences in the value of reactive FMD (6.6 $\pm 2.2 \%$ vs. 9.5 $\pm 2.9 \%, p<0.001)$ between groups $A$ and $B$, and the same differences were observed with nitroglycerine (NTG)induced dilatation (14.6 $\pm 4.7 \%$ vs. $18.0 \pm 5.8 \%, p=0.013)$. The intraobserver and inter-observer variability for repeated measurements were $0.02 \pm 0.06 \mathrm{~mm}$ and $0.03 \pm 0.15 \mathrm{~mm}$, respectively. The intra-observer regression coefficient was 0.87 and the inter-observer regression coefficient was 0.85 for echocardiographic measurements.

\section{Correlation between the parameters of stress and myocardial or endothelial function}

Global severity index showed significant correlations with GLS ( $r=$ $0.384, p=0.002)$. The value of GLS correlated robustly with the nine 
Table 3. Correlations between parameters of stress and vascular parameters

\begin{tabular}{|c|c|c|c|c|c|c|}
\hline & & & & & NTG ind & \\
\hline & $r$ & $p$ & $r$ & p & $r$ & $p$ \\
\hline Somatization & 0.141 & 0.265 & -0.365 & 0.003 & -0.241 & 0.055 \\
\hline Compulsivity & 0.376 & 0.002 & -0.486 & $<0.001$ & -0.286 & 0.022 \\
\hline Interpersonal sensitivity & 0.329 & 0.008 & -0.550 & $<0.001$ & -0.303 & 0.015 \\
\hline Depression & 0.330 & 0.008 & -0.427 & $<0.001$ & -0.329 & 0.057 \\
\hline Anxiety & 0.402 & 0.001 & -0.484 & $<0.001$ & -0.348 & 0.006 \\
\hline Hostility & 0.075 & 0.565 & -0.232 & 0.072 & -0.016 & 0.902 \\
\hline Phobic anxiety & 0.405 & $<0.001$ & -0.441 & $<0.001$ & -0.305 & 0.017 \\
\hline Paranoid ideation & 0.472 & $<0.001$ & -0.486 & $<0.001$ & -0.363 & 0.004 \\
\hline Psychoticism & 0.210 & 0.105 & -0.519 & $<0.001$ & -0.362 & 0.004 \\
\hline Post stress disorder index & 0.294 & 0.022 & -0.423 & 0.001 & -0.328 & 0.010 \\
\hline Global severity index & -0.384 & 0.002 & -0.583 & $<0.001$ & -0.342 & 0.006 \\
\hline
\end{tabular}

LV: left ventricular, FMD: flow-mediated dilatation, NTG: nitroglycerine
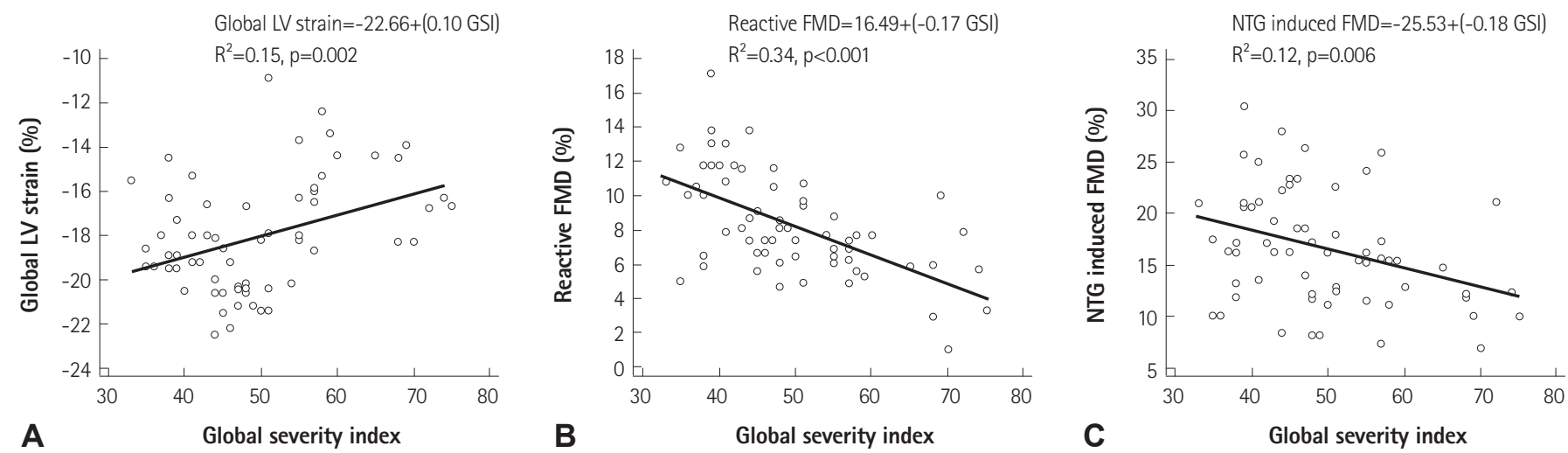

Fig. 2. Correlations between stress intensity and global left ventricular (LV) strain (A) and endothelial parameters (B and C). The value of global LV strain and FMD/NTG-induced dilatation showed significant correlation with global severity index. FMD: flow-mediated dilatation, NTG: nitroglycerine, GSI: global severity index.

items of the SCL-90-R, with the significant correlations being with paranoid ideation $(r=0.472, p<0.001)$, phobic anxiety $(r=0.405, p<$ $0.001)$, anxiety $(r=0.402, p=0.001)$, compulsivity $(r=0.376, p=0.002)$, depression ( $r=0.330, p=0.008)$, and interpersonal sensitivity ( $r=$ 0.329, $p=0.008$ ). Somatization, hostility, and psychoticism showed poor correlation with GLS (Table 3). GSI also showed significant correlations with reactive FMD $(r=-0.583, p<0.001)$ and NTG-induced FMD ( $r=-0.342, p=0.006)$ (Fig. 2). Multivariate linear regression analysis showed that GSI was the only significant attributor to GLS ( $\beta=$ $0.149, p=0.008)$ and reactive $F M D(\beta=-0.200, p=0.041)$. However, age was the only significant attributor to NTG-induced FMD (Table 4).

\section{Discussion}

In this study, we demonstrated for the first time that myocardial longitudinal deformation and endothelial function is reduced in patients with chronic emotional stress, as assessed by the two-dimen- sional strain echocardiography and FMD. In addition, decreases in LV function and endothelial function were independently related to the severity of stress intensity as determined by the validated questionnaire, SCL-90-R.

There were no differences between the groups in conventional two-dimensional echocardiographic parameters, including ejection fraction, fractional shortening, relative LV wall thickness, LV mass index, and diastolic function, according to the severity of stress. However, global and segmental longitudinal LV strains were significantly reduced in the higher stress group. The longitudinal peak systolic strain/strain rate has been shown to be linearly correlated with the maximal value of the first LV filling pressure time derivative and with the peak elastance, which are both global measures of LV systolic function and contractility. Two-dimensional strain, as determined by speckle tracking, has recently been used for the quantitative evaluation of LV function. This method has been validated for the evaluation of longitudinal LV function. ${ }^{211}$ Subclinical LV dys- 
Table 4. Multiple linear regression analysis for parameters of stress and vascular parameters

\begin{tabular}{|c|c|c|c|c|c|c|}
\hline & \multicolumn{3}{|c|}{ Univariate analysis } & \multicolumn{3}{|c|}{ Multivariate analysis } \\
\hline & Beta & $95 \% \mathrm{Cl}$ & $p$ & Beta & $95 \% \mathrm{Cl}$ & $p$ \\
\hline Age & -0.008 & 0.068 to 0.064 & 0.950 & 0.052 & -0.012 to 0.116 & 0.102 \\
\hline Mean blood pressure & 0.031 & -0.026 to 0.089 & 0.280 & -0.022 & -0.131 to 0.088 & 0.679 \\
\hline Body mass index & 0.123 & -0.128 to 0.373 & 0.327 & 0.022 & -0.279 to 0.322 & 0.879 \\
\hline Total cholesterol & 0.000 & -0.029 to 0.029 & 0.980 & 0.007 & -0.027 to 0.041 & 0.671 \\
\hline hs-CRP & 0.063 & -0.026 to 0.352 & 0.658 & 0.057 & -0.226 to 0.340 & 0.675 \\
\hline Global severity index & 0.094 & 0.036 to 0.151 & 0.002 & 0.149 & 0.041 to 0.256 & 0.008 \\
\hline \multicolumn{7}{|c|}{ Global LV strain ( $R^{2}=0.491$, adjusted $R^{2}=0.288$ in multivariate analysis) } \\
\hline Age & -0.086 & -0.160 to -0.012 & 0.023 & 0.072 & -0.042 to 0.185 & 0.198 \\
\hline Mean blood pressure & -0.023 & -0.090 to 0.044 & 0.498 & 0.021 & -0.112 to 0.154 & 0.745 \\
\hline Body mass index & -0.096 & -0.388 to 0.197 & 0.513 & -0.004 & -0.523 to 0.515 & 0.988 \\
\hline Total cholesterol & 0.009 & -0.025 to 0.042 & 0.602 & 0.008 & -0.047 to 0.062 & 0.768 \\
\hline hs-CRP & -0.040 & -0.426 to 0.346 & 0.831 & 0.018 & -0.422 to 0.457 & 0.932 \\
\hline Global severity index & -0.166 & -0.225 to -0.107 & $<0.001$ & -0.200 & -0.378 to -0.022 & 0.041 \\
\hline \multicolumn{7}{|c|}{ Reactive FMD ( $R^{2}=0.433$, adjusted $R^{2}=0.207$ in multivariate analysis) } \\
\hline Age & -0.170 & -0.308 to -0.032 & 0.016 & -0.210 & -0.339 to -0.081 & 0.016 \\
\hline Mean blood pressure & -0.004 & -0.121 to 0.112 & 0.940 & -0.047 & -0.270 to 0.177 & 0.177 \\
\hline Body mass index & 0.102 & -0.403 to 0.608 & 0.685 & 0.502 & -0.370 to 1.374 & 0.239 \\
\hline Total cholesterol & 0.039 & -0.016 to 0.095 & 0.161 & 0.060 & -0.032 to 0.151 & 0.187 \\
\hline hs-CRP & -0.448 & -1.131 to 0.235 & 0.188 & -0.239 & -0.978 to 0.499 & 0.501 \\
\hline Global severity index & -0.182 & -0.308 to -0.055 & 0.006 & -0.057 & -0.356 to 0.243 & 0.693 \\
\hline
\end{tabular}

$\mathrm{Cl}$ : confidence interval, hs-CRP: high-sensitivity C-reactive protein, FMD: flow-mediated dilatation, NTG: nitroglycerine, LV: left ventricular

function relates to the structure-function relationship and characterizes a preclinical stage of myocardial damage. This damage can be detected by a decrease in longitudinal myocardial function and the vulnerability of subendocardial fibers, which occurs before the development of abnormalities in conventional measures of LV performance. ${ }^{22)}$

Several mechanisms of myocardial damage concomitant with or downstream to the SNS activation have been proposed. Recent data suggest that elevated systemic levels of catecholamines are central to the pathophysiology of this disorder. ${ }^{23)}$ However, the exact mechanism of catecholamine-induced myocardial damage is thought to be multifactorial. The postulated mechanisms include persistent activation of calcium channels, membrane damage, and microvascular spasm. ${ }^{24)}$ Microvascular endothelial dysfunction can sensitize coronary circulation to the vasoconstrictor effects of catecholamines. ${ }^{25}$ Microvascular spasm and cardiac syndrome $X$ are disorders predominantly associated with women, and particularly, postmenopausal women. ${ }^{26)}$ Similar gender differences can be seen in transient LV dysfunction. In peripheral circulation, microvascular abnormalities are exacerbated by sympathetic nerve activation. ${ }^{27)}$

Chronic stress might be associated with impaired endothelial function. A variety of stimuli acutely influence FMD: a single highfat meal and postprandial lipemia, mental stress, ${ }_{1}^{3)}$ and probably by catecholamines, circulating levels of estrogen and progesterone, ${ }_{1}^{28)}$ smoking, acute changes in glucose, and changes in sodium and calcium. In the present study, we compared FMD in high and low stress groups and evaluated the factors affecting endothelial function in patients with stress. Patients with higher stress exhibited decreased endothelial-dependent vasodilatation and endothelial-independent vasodilatation, and these parameters paralleled the severity of stress. Endothelial dysfunction is reflected by an impaired FMD response, which is determined from the forearm and coronary circulation. A vasodilatory stimulus is applied to the downstream vascular bed, eliciting flow-dependent dilatation of the upstream conduit vessel. As a control, the response of the brachial artery to sublingual nitroglycerine dilatation is recorded. The duration and the amplitude of brachial artery dilatation in response to NTG are more pronounced than during FMD. Our result showed that the severity of stress was the only significant attributor to reactive FMD, but not to NTG-induced FMD. With an increasing number of cardiovascular risk factors, smooth muscle dysfunction becomes apparent; thus, NTG response is progressively impaired independently from endothelial dys- 
function. ${ }^{29)}$

Considering the strong correlation between stress parameters and LV strain/FMD, further clinical evaluation of myocardial and endothelial function with long-term follow-up is necessary, especially for patients with high initial stress levels. Given the association of physical or emotional stresses in patients with transient LV dysfunction, chronic stress may play a role in the change of LV function.

There are some limitations to this study. The number of patients in this study was relatively small, and the real duration of stress experienced by study subjects was not known.

Secondary, although we tried to exclude patients with ischemic heart disease according to the normal coronary angiography or negative Treadmill test, all subjects were not confirmed by coronary angiography; therefore, we cannot completely exclude the presence of significant coronary artery disease. As well-known, women tend to be false-negative in exercise stress test especially in patients without left anterior descending artery stenosis. Moreover, we did not check the coronary flow reserve or adenosine-stress MRI to exclude microvascular angina, which is a very common cause of atypical chest pain in postmenopausal women. However, microvascular angina have been found to present high levels of neuritucusm, i.e., anxiety, depression and somatic concerns, and our result may add the possible mechanism of atypical chest pain in microvascular angina. Although we assessed the severity of stress by questionnaire, a more objective assessment, such as functional magnetic resonance imaging or MIBG scanning is needed. In addition, the reversibility of LV functional impairment and endothelial dysfunction after stress treatment should be clarified through larger randomized studies.

In conclusion, chronic emotional stress may exert negative effects on LV and endothelial function, which might be associated with the severity of stress. This study provides a possible mechanism by which stress may be associated with an increased risk of cardiovascular dysfunction. However, longitudinal studies employing a large population are required to determine the pathophysiology and prognostic implications of endothelial dysfunction in patients with chronic stress.

\section{Acknowledgments}

This study was supported by a grant from the Korean Society of Circulation (Industrial-educational cooperation 2011).

\section{References}

1. Selye H. The stress of life. New York: McGraw Hill;1956.

2. Grippo AJ, Johnson AK. Stress, depression and cardiovascular dysregulation: a review of neurobiological mechanisms and the integration of research from preclinical disease models. Stress 2009;12:1-21.
3. Ghiadoni L, Donald AE, Cropley M, et al. Mental stress induces transient endothelial dysfunction in humans. Circulation 2000;102:2473-8.

4. Spieker $L E$, Hürlimann D, Ruschitzka F, et al. Mental stress induces prolonged endothelial dysfunction via endothelin-A receptors. Circulation 2002;105:2817-20.

5. Henry JP, Ely DL, Stephens PM, Ratcliffe HL, Santisteban GA, Shapiro AP. The role of psychosocial factors in the development of arteriosclerosis in CBA mice. Observations on the heart, kidney and aorta. Atherosclerosis 1971;14:203-18.

6. Strawn WB, Bondjers G, Kaplan JR, et al. Endothelial dysfunction in response to psychosocial stress in monkeys. Circ Res 1991;68:1270-9.

7. Lawrence RC, Helmick CG, Arnett FC, et al. Estimates of the prevalence of arthritis and selected musculoskeletal disorders in the United States. Arthritis Rheum 1998;41:778-99.

8. Rozanski A, Blumenthal JA, Davidson KW, Saab PG, Kubzansky L. The epidemiology, pathophysiology, and management of psychosocial risk factors in cardiac practice: the emerging field of behavioral cardiology. J Am Coll Cardiol 2005;45:637-51.

9. Tofler GH, Muller JE. Triggering of acute cardiovascular disease and potential preventive strategies. Circulation 2006;114:1863-72.

10. Pang KY. Hwabyung: the construction of a Korean popular illness among Korean elderly immigrant women in the United States. Cult Med Psychiatry 1990;14:495-512.

11. Park YJ, Kim HS, Schwartz-Barcott D, Kim JW. The conceptual structure of hwa-byung in middle-aged Korean women. Health Care Women Int 2002;23:389-97.

12. Celermajer DS, Sorensen KE, Bull C, Robinson J, Deanfield JE. Endothelium-dependent dilation in the systemic arteries of asymptomatic subjects relates to coronary risk factors and their interaction. J Am Coll Cardiol 1994;24:1468-74.

13. Baum A. Stress, intrusive imagery, and chronic distress. Health Psychol 1990;9:653-75.

14. Corretti MC, Anderson TJ, Benjamin EJ, et al. Guidelines for the ultrasound assessment of endothelial-dependent flow-mediated vasodilation of the brachial artery: a report of the International Brachial Artery Reactivity Task Force. J Am Coll Cardio/ 2002;39:257-65.

15. Derogatis LR, Meyer JK, Kourlesis S. Psychiatric diagnosis and psychological symptoms in impotence. Hillside J Clin Psychiatry 1985;7:120-33.

16. Kim KI, Kim JH, Won HT. Korean manual of Symptom Checklist-90-Revision. Seoul: Choong Ang Aptitude Publishing Co;1984. p.1-39.

17. Boudrez H, De Backer G. Psychological status and the role of coping style after coronary artery bypass graft surgery. Results of a prospective study. Qual Life Res 2001;10:37-47.

18. Skydsbjerg M, Lunn S, Hutchings B. Psychosocial aspects of human immunodeficiency virus (HIV) infection in a pre-HAART sample. Scand J Psychol 2001;42:327-33.

19. Hwang JW, Hahm BJ, Kwon ST, Kim KH, Lee JR. Impact of lifetime subthreshold depression and major depression before internship on psychopathology and quality of life in Korean interns: 6 month follow-up study. Aust N ZJ Psychiatry 2008;42:301-8.

20. Hardt J, Gerbershagen HU, Franke P. The symptom check-list, SCL90-R: its use and characteristics in chronic pain patients. Eur J Pain 2000;4:137-48. 


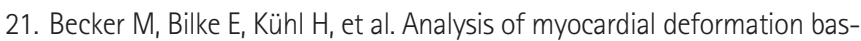
ed on pixel tracking in two dimensional echocardiographic images enables quantitative assessment of regional left ventricular function. Heart 2006;92:1102-8.

22. Chan J, Hanekom L, Wong C, Leano R, Cho GY, Marwick TH. Differentiation of subendocardial and transmural infarction using two-dimensional strain rate imaging to assess short-axis and long-axis myocardial function. J Am Coll Cardio/ 2006;48:2026-33.

23. Wittstein IS, Thiemann DR, Lima JA, et al. Neurohumoral features of myocardial stunning due to sudden emotional stress. N Engl J Med 2005; 352:539-48.

24. Zaroff JG, Rordorf GA, Titus JS, et al. Regional myocardial perfusion after experimental subarachnoid hemorrhage. Stroke 2000;31:1136-43.

25. Vita JA, Treasure CB, Yeung AC, et al. Patients with evidence of coro- nary endothelial dysfunction as assessed by acetylcholine infusion demonstrate marked increase in sensitivity to constrictor effects of catecholamines. Circulation 1992;85:1390-7.

26. Mohri M, Koyanagi M, Egashira K, et al. Angina pectoris caused by coronary microvascular spasm. Lancet 1998;351:1165-9.

27. Ako J, Kozaki K, Yoshizumi M, Ouchi Y. Transient left ventricular apical ballooning without coronary artery stenosis: a form of stunning-like phenomenon. J Am Coll Cardiol 2002;39:741-2.

28. Harris KF, Matthews KA, Sutton-Tyrrell K, Kuller LH. Associations between psychological traits and endothelial function in postmenopausal women. Psychosom Med 2003;65:402-9.

29. Adams MR, Robinson J, McCredie R, et al. Smooth muscle dysfunction occurs independently of impaired endothelium-dependent dilation in adults at risk of atherosclerosis. J Am Coll Cardio/ 1998;32:123-7. 